\title{
Benutzerhinweise zum Einordnen der 5. Lieferung
}

Die 5. Lieferung bitten wir, entsprechend den nachstehend aufgeführten Hinweisen einzuordnen.

Achtung! Während des Satzes der 5. Lieferung ist eine Reihe von Rechtsvorschriften außer Kraft getreten. Der durch ihre Herausnahme aus dem Umbruch der 5. Lieferung entstandene freie Platz wurde zur Aufnahme neuer Bestimmungen genutzt. Aus technischen Gründen stimmt daher die Folge der Registernummern im Kapitel C im Textteil nicht mit der des Kapitelinhaltsverzeichnisses überein.

Es wird gebeten, dies bei der Einordnung besonders zu beachten.

Zu entfernen

Einzuordnende Teile der ๖. Lieferung

Kontrollblatt

S. $1-2$

Ergänzungsinhaltsverzeichnis

Kapitel B

B 0111 Int.

B 0112 Int.

B 0631

B 0633

B 0634

B 0641

B 0644

B 0645

Ergänzungsinhaltsverzeichnis

Kapitel C

C 020401

C 020402

C 020405

C 020450

C 020460
S. $1-2$

S. $1-14$

S. $1-2$

S. $1-13$

S. $1-9$

S. $1-7$

S. $1-4$

S. $1-3$

S. $1-5$

S. 1-11

S. $1-10$

S. $1-2$

S. $1-6$

S. $1-2$

S. $1-6$ 